\title{
Bacterial vaccines in poultry
}

\author{
Nagwa S. Rabie* (i) and Zeinab M. S. Amin Girh
}

\begin{abstract}
Background: Poultry bacterial pathogens are mainly controlled by using high-cost sanitary measures and medical treatment. However, the drug-resistant strains of pathogens continuously emerge, and medical treatments are often ineffective. Moreover, there is increasing public objections to drug residues in poultry products. The other important type of control is the vaccination which depends on immunity. This immunological control is the major practical alternative to chemotherapy. Success of vaccines in combating poultry diseases depends mainly on the choice of the proper type of vaccines, correct time of its usage, and method of administration.

The types of vaccines include attenuated live vaccines, and these vaccines were shown to be effective in inducing protection. The second type is killed vaccine or whole bacteria extracts which is less successful in providing protection compared to live vaccines. The metabolic product vaccine (toxoids) is the third type of vaccine. The recombinant DNA technique was adopted to produce the protective antigens in a sufficient amount and in costeffective ways.

Conclusions: Protection studies against bacterial diseases were performed by using several trials: living vaccines (live attenuated vaccines; live, non-pathogenic microorganisms; live, low virulence microorganism), inactivated (killed) vaccines (heat-inactivated, chemical inactivates, radiation), metabolic product vaccines (toxoids), subunit vaccines (whole cell proteins, outer membrane proteins, purified flagellar proteins (flagellin), fimbrial proteins, pilus proteins, lipopolysaccharides), vaccines produced by recombinant deoxyribonucleic acid (DNA) technology, and DNA vaccines.
\end{abstract}

Keywords: Poultry, Bacterial vaccines, Live vaccines, Inactivated vaccines, Subunit vaccines, DNA vaccines

\section{Introduction}

Bacterial infections of poultry are a worldwide important factor in terms of their economic losses and public health. The control of these diseases depends on highcost sanitary measures and medical treatment. However, the appearance of bacterial strains resistant to these drugs may be due to the overuse of antibiotics as well as due to care about the effect of drugs and their residues on poultry products. Moreover, some organisms are naturally resistant to most antibiotics (Nakae et al. 1997), and all these reasons led to searching for other immunological means of control. One of which was vaccination which was found very effective in providing protection against bacterial diseases. The protection effect of bacterial vaccines depends on the immune response of the host towards different antigenic components of the bacteria. Antigens stimulate humoral immunity (mainly B

\footnotetext{
* Correspondence: nagwasrabie@hotmail.com

Department of Poultry Diseases, National Research Centre, 33 Bohouth St, Dokki, Giza, Egypt
}

cells, which give rise to antibodies and cooperate with eosinophils, macrophages and neutrophils) and cellmediated immunity (mainly $\mathrm{T}$ cells, which produce lymphokines). Bursa of Fabricius and the thymus serve as the primary lymphoid organs of the immune system. B cells use surface immunoglobulins as antigen receptors and differentiate into plasma cells to secrete antibodies. Three classes of antibodies are produced: IgM, IgG (also called IgY), and IgA. Successful vaccinal response in a flock is often monitored by demonstrating a rise in antibody titer within a few days of vaccination. ELISA is used most commonly for serologic monitoring. $\mathrm{T}$ cells are the principal effector cells of specific cellular immunity. $\mathrm{T}$ cells differentiate into alpha beta and gamma delta cells. In adult birds, gamma delta cells may constitute up to $50 \%$ of the circulating $\mathrm{T}$ cells. Functionally, CD4+ cells serve as helper cells and CD8+ cells as cytotoxic/suppressor cells (Sharma 1999).

The development of bacterial vaccines depends on different techniques, live or inactivated (killed) forms of 
bacteria. Live attenuated vaccines against several poultry diseases provided protection and were commercially available. Some of these diseases are mycoplasmosis in turkeys and chickens caused by Mycoplasma gallisepticum (M. gallisepticum) (Ley et al. 1997) or Mycoplasma synoviae (M. synoviae) (Morrow et al. 1998), fowl typhoid caused by Salmonella enteritidis (S. entertidis) (Babu et al. 2003) or Salmonella gallinarium (S. gallinarum) (Barrow et al. 2000). Paratyphoid caused by Salmonella typhimurium (S. typhimurium) (Bachtiar et al. 2003), colibacillosis caused by Escherichia coli (E. coli) (Peighambari and Gyles 1998), and fowl cholera caused by Pasteurella multocida (P. multocida) (Scott et al. 1999). Some of the disadvantages of live attenuated vaccines are that they are based on living organisms which face problems in preparation (as contamination) and batch uniformity. They provide limited immunity if severely attenuated and may cause diseases if insufficiently attenuated.

Other forms of living vaccines prepared from nonpathogenic microorganisms as in salmonellosis (Hassan and Curtiss 1997), colibacillosis (Frommer et al. 1994), and low virulent microorganisms as in campylobacteriosis caused by Campylobacter jejuni (C.jejuni) (Ziprin et al. 2002) gave no protection.

Inactivated (killed) vaccines are prepared from whole bacterial preparation combined with an adjuvant. They are inactivated by either heat at $60^{\circ} \mathrm{C}$ for $1 \mathrm{~h}$ as in campylobacteriosis (Widders et al. 1998) or chemicals as in samonellosis (Duchatel et al. 1998) and in fowl cholera (Khafagy et al. 1999) or radiation as in Pseudomonas infection (Mohamed et al. 2002).

Metabolic product vaccines as toxoids (Fukutome et al. 2001) and subunit vaccines are prepared from outer membrane proteins (Abd-Aty and Rabie 2003) whole-cell proteins and flagellin (Rabie and Zou El Fakar, 2004), fimbrial and pilus proteins, and lipopolysaccharids (Shujian et al. 1996).

Recombinant DNA technology as in salmonellosis (Dueger et al. 2003) and DNA vaccines are used mainly in viral infections.

\section{Traditional techniques of bacterial vaccine production}

Conventional methods of bacterial vaccine development is based on whole bacteria, and they are divided into two groups: living vaccines and inactivated (killed) vaccines.

\section{Living vaccines}

\section{Live attenuated vaccines}

In this type of vaccine, the living microorganisms are either avirulent or rendered avirulent by attenuation; this means that these pathogens are capable of multiplication within the host but are incapable of causing diseases.
Live attenuated bacteria simulate natural infection which increases cell-mediated immune response. Immunization of day-old chicks with the attenuated S. typhimurium live vaccine strain resulted in the same change in $\mathrm{T}$ cell composition as seen after infection with the nonattenuated salmonella wild-type strain, but at a lower level except an increase of $\mathrm{CD}_{8+} \mathrm{TCR}_{1+}$ (gamma delta) double-positive cells which have an important role in the immunological defense of chickens against salmonella exposure (Berndt and Methner 2001). S. enteritidis live attenuated vaccine was more effective in increasing $\mathrm{T}$ lymphocyte proliferation than killed vaccine in laying hens (Babu et al. 2003). Vaccination of layer chickens with a live attenuated S. gallinarum 9 R strain reduced $S$. enterica infections and the vaccine could not spread to the egg content (Faberwee et al. 2001). The live Mycoplasma gallisepticum (M. gallisepticum) vaccine strains ts-11 and 6/85 could be transmitted from vaccinated layer pullets to unvaccinated pullets, broiler breeders, turkey breeders, or meat turkeys which were in indirect contact with them (Ley et al. 1997).

The pathogenic live bacteria was attenuated by mutagenesis Chemical mutagenesis of bacteria by using $\mathrm{N}$-methyl $\mathrm{N}^{\prime}$-nitro-N nitroguanidine (NTG) for production of clones with a temperature sensitive (ts) and used as a vaccine candidate in Mycoplasma synoviae (M. synoviae) in chickens (Morrow et al. 1998; Markham et al. 1998) and Ornithobacterium rhinotracheale (O. rhinotracheale) in turkeys (Lopes et al. 2002). Broiler chicken breeders were vaccinated with a temperature sensitive mutant of $M$. gallisepticum; the vaccine prevented infection in tracheas and infra orbital sinuses of these breeders and in vitelline membrane of their embryos. In addition, the broiler offsping of the vaccinated breeders had better production performance (Barbour et al. 2000).

Intramuscular administration of the aro A-ser C (aromatic dependent mutants) of the lysogenic strain of S. gallinarium induced protection against experimental fowl typhoid (Barrow et al. 2000). An aro A-attenuated mutant of $S$. Typhimurium vaccine was used as heterologous antigen delivery and prevent salmonellosis in chickens (Bachtiar et al. 2003). Attenuated live vaccine was prepared from respiratory chain muations (nuoG, 47GyoA, atpB, and at $\mathrm{pH}$ ) of three Salmonella enterica servoars Typhimurium, Gallinarum and Dublin in chickens and mice (Turner et al. 2003). Attenuated derivatives (Delta Cya Delta crp mutants) of $\mathrm{O} 2$ and $\mathrm{O} 78$ avain septisemic Escherichia coli (E. coli) strain were used to immunized broiler chickens by spraying. The mutant $\mathrm{O} 2$ strain provided moderate protection against airsacculitis but not the O78 strain (Peighambari et al. 2002). Live attenuated streptomycin-dependent (str-dependent) mutants derived 
from a virulent APEC did not cause mortality in challenged birds and systemic lesions were significantly reduced when birds were given three vaccinations on days 1 (aerosol), 14 (oral), and 28 (oral) (Amoako et al. 2004).

Vaccination of fattening turkey flock with live commercial S. enteritidis at day 1 of age via spray and boostered at 6 and 11 weeks of age via drinking water did not reduce shedding or colonization of internal organs when birds were challenged with $S$. enteritidis PT4 (Krüger et al. 2008).

\section{Live, non-pathogenic microorganisms}

A live, non-pathogenic piliated strain of $E$. coli was reported to be effective when broilers were vaccinated by the oral or intramuscular route at 14 or 21 days of age and challenged by the intramuscular route 1 week later with virulent avian pathogenic $E$. coli while vaccination by spraying did not induce adequate protection (Frommer et al. 1994).

Oral immunization with Haemophilus somnus vaccine protected broilers from infection with virulent strains of S. enteritidis (Wieliczko et al. 2000).

Attenuated or avirulent bacteria can be used as vehicles for the effective delivery of vaccine candidates (Rappuoli et al. 2011). Attenuated Salmonella strains are often used in poultry for the control of salmonellosis and they can serve as safe and effective oral carrier vaccines to prevent NE by expressing heterologous antigens (Jiang et al. 2015).

\section{Live, low virulence microorganism}

Intravenous infection of pigeons with the low virulence Streptococcus gallolyticus (S. gallolyticus) serotype I strain PDH827 did not induce clinical protection against challenge with high virulence serotype I strain STR357 (Kimpe et al. 2002). The treatment of chicks with viable non-colonizing strains of $C$. jejuni intramuscularly as a possible vaccine with or without adjuvant was failed to induce protective immunity (Ziprin et al. 2002).

\section{Inactivated (killed) vaccines}

Inactivated vaccines are generally whole bacterial preparations combined with an adjuvant and the cultured pathogens are rendered non-infectious by killing and are used for immunization. Killed bacterial vaccine are called bacterin, and killing microbial pathogens is achieved by using one of the following methods:

\section{Heat inactivated $\left(60^{\circ} \mathrm{C}\right.$ for $\left.1 \mathrm{~h}\right)$}

Vaccination of broilers and layers with Tribactopulvis heat inactivated vaccine which was prepared from Salmonella, E. coli, and P. aeruginosa resulted in reduction in death by $30-50 \%$, increasing in weights $100-200 \mathrm{~g}$ and less coccidiosis and infectious bronchitis in vaccinated birds (Cambir 1999). Chick embryos were orally immunized at day 16 of incubation by injection of heat-killed C. jejuni organisms into the amniotic fluid which increased antibody response in hatched chicks (Noor et al. 1995) which was higher than that of embryos immunized with soluble C. jejuni antigen (Noor 1998). Effective inactivated E.coli vaccines against serotypes including $\mathrm{O} 2: \mathrm{Kl}$ and O78:K80 have been produced and provide protection against the homologous serogroups not against heterologous serogroups (Saif et al. 2003).

\section{Chemical inactivants}

They are protein denaturants as formaldehyde, acetone, and alcohol or alkalyating agents as ethylene oxide, ethyleneimine acetylmethylimine, and $\beta$-propriolactone. Chickens were vaccinated with formalized antigen of $C$. jejuni with or without immunodulator reduced reisolation of $C$. jejuni from internal organs but did not protect chicks (Rabie and Kutkat 2002). Pigeons were vaccinated with killed vaccines containing whole cell formaldehydeinactivated S. typhimurium Var. Copenhagen. The vaccine could not induce protection against challenge but only reduced fecal shedding (Vereechen et al. 2000). Vaccination of rabbits with a saponin killed vaccine of Mycoplasma mycoids resulted in increased humoral immune response (Sunder et al. 2001). Inactivated S. enteritidis phagotype four vaccines (emulsified in light mineral oils or adsorbed in aluminum hydroxide) were used in 1-day-old chicks; no reisolation of S. enteritidis from cloacal swabs could be abtained after challenge. The vaccines emulsified in mineral oils produced greater antibodies compared to that prepared by adsorption into aluminum hydroxide (Fernchini et al. 1997). Autogenous in activated tissue vaccine (from the liver and spleen of diseased chickens) to be an approach to the prevention of ascites syndrome in broilers in which four bacterial strains were isolated and the E. coli was the most commonly isolated strain (Shuxia et al. 1999). Avian Salmonella oil vaccine was used in day-old Japanese quail by S/ $\mathrm{C}$ and $\mathrm{I} / \mathrm{M}$ injection. No deaths were observed and weak immunological reaction was detected. The egg production was lower only during the period of $6-10$ weeks after vaccination (Ito et al. 2000). The comparative efficacy of oil-based and gel-based vaccine adjuvants has been studied by other researchers. Some studies demonstrated that an oil-based vaccine induced a higher antibody level and provided better protection against field strains (Jacobs et al. 1992; Fukanoki et al. 2000; Chukiatsiri et al. 2010; Gong et al. 2014).

\section{Radiation}

Immunization of chicks with gamma irradiated (cobalt 60) bivalent Pseudomonoas aeruginosa (Ps. aeruginosa) 
vaccine recorded protection by $100 \%, 96 \%$, and $90 \%$ post challenge intramuscular, subcutaneously and orally vaccinated chicken groups, respectively; also, the vaccination of layers with the same vaccine stimulated the formation and concentration of $P$. aeruginosa-specific Igy in the egg yolk (Mohamed et al. 2002). Chickens were immunized intraocular with liposome associated $S$. enteritidis antigen; the antigen was prepared by ultrasonicated whole cell extract of the bacteria. The vaccine induced increase in the specific antibody producing lymphocytes in the intestinal tract and immunoglobulin secreted in the intestine inhibited the adherence of the bacteria to intestinal epithelial cells suppressing the spread of the bacterial infection in the host (Fukutome et al. 2001).

Combined bacterins Two mixed bacterins from E. coli, Staphylococcus aureus, and Clostridium perifringens (C. perifringens) or Clostridium septicum (C. septicum) were used for immunization of chickens against gangrenous dermatitis; the vaccines were found to be safe and they protected the birds against challenge with live cultures of the bacteria without any untoward reactions (Kaul et al. 2001)

Both the heat and formalin inactivated aluminum precipitated vaccines prepared with the virulent $E$. coli isolates was effective to protect chickens of different age against various forms of avian colibacillosis (Rashid et al. 2001). A developed combined vaccine was prepared from trivalent $E$. coli vaccine (serotypes $\mathrm{O} 1, \mathrm{O} 2$, and O78) and an inactivated Newcastle disease vaccine induced a high degree of protection in layers and chicks (Erganis et al. 2002).

Simultaneous use of inactivated and live vaccines The use of a live $P$. multocida vaccine followed by a killed $P$. multocida vaccine, two live vaccines, or a killed vaccine followed by live vaccine provides almost equal immunity when measured by enzyme-linked immunosorbent assay (ELISA) titers (Hofacre et al. 1987). Parent chickens were vaccinated with live S. typhimurium and inactivated S. enteritidis induced an increase in antibody concentration in sera and jejunum of the chicks (Mathner et al. 2002). Laying hens should be vaccinated with live and killed vaccines to stimulate mucosal and systemic immunity and reduce the prevalence of $S$. enteritidis-contaminated eggs (Davies and Breslin 2004).

\section{Metabolic product vaccines (toxoids)}

These are soluble toxins that are rendered harmful (non-toxin) by addition of formalin or by gentle heating; this way does not affect the immunogenic properties of the toxin. Ducks were immunized with a type of botulinum toxin; it induced partial protection but in a single dose while double dose vaccine increased signs of botulism and the vaccine can be used to wild birds during botulism epizootics (Rock et al. 2000). Samonella toxins (enterotoxin plus cytotoxins) were the main virulent products of the organisms formalized (FT) and carbonated $(\mathrm{CT})$ toxoids were prepared from partially purified toxins of S. enterica ser. weltevreden and Gallinarum. Complete protection could be obtained in birds vaccinated with FT of $S$. weltevreden plus Freund's complete adjuvant (FCA) following homologous or heterologous (S. gallinarum and S. typhimurium) challenges while protection ranged from 50 to $83.3 \%$ in the groups immunized with other preparations of $S$. weltevreden, i.e., with FT without FCA or with CT with or without FCA. Gallinarum toxins (FT) given with FCA afforded $100 \%$ protection against homologous challenge, but not against heterologous serovars (Mishra and Sharma 2001). Chicks received vit. E adjuvant salmonella toxoid; high lymphocyte stimulation was recorded and the vaccinated chicks were protected against Salmonella challenge (Barman et al. 2000). Several trials have shown that chickens could be protected against $C$. perfringens-induced necrotic enteritis (NE) by injection with inactive and active toxins (Jang et al. 2012; Kulkarni et al. 2007) and antigenic proteins (Jiang et al. 2015).

\section{Subunit vaccines}

They are prepared from one or few immunogenic epitopes that are found an infectious agent. Among the surface epitopes of an entigen molecule, few epitopes are important in stimulating protective immunity.

\section{Whole-cell proteins}

Immunization of chickens with surface antigens proteins of $E$. coli induced highly systemic and mucosal antibody responses (Kariyawasam et al. 2002). Ammonum sulfate perceptible protein (ASPP) of Pasteurella multocida serotype 6 B yielded three protein fractions, which can be used to develop a subunit vaccine against haemorrhagic septicemia in rabbits (Srivastava 1999). S. enteritidis OMPs of 75.6 and $82.3 \mathrm{KDa}$ were effective in reducing colonization of $S$. enteritidis on intestinal mucosa in chickens (Khan et al. 2003). Chicks were immunized with $C$. jejuni OMPs vaccine $(44-80 \mathrm{KDa})$; it reduced the infection after challenge and increased the serum antibody titer (Abd-Aty and Rabie 2003).

\section{Outer membrane proteins (OMPs)}

Forty-five kilodaltons protein is considered to be a major OMP of $C$. jejuni and has immunogenic effect in chickens (Lam 1992). The immunodominant protein antigen of $C$. jejuni is subunit molecular weight of 59 to $61 \mathrm{KDa}$ (Dubreuil et al. 1990). Chicks were immunized with $C$. jejuni OMPs vaccine $(44-80 \mathrm{KDa})$; it reduced the 
infection after challenge and increased the serum antibody titer (Abd-Aty and Rabie 2003). S. enteritidis OMPs of 75.6 and $82.3 \mathrm{KDa}$ were effective in reducing colonization of $S$. enteritidis on intestinal mucosa in chickens (Khan et al. 2003).

\section{Purified flagellar proteins (flagellin)}

Immunization of broiler chicks with purified native flagellin or combined heat killed $C$. jejuni and flagellin induced reduction in the number of Campylobacter in caecal contents. Flagellin $(61-63 \mathrm{KDa})$ and possibly the $67 \mathrm{KDa}$ antigen may be valuable for immunological control of C. jejuni and used as vaccine candidates. (Widders et al. 1998). Flagella and whole cell extraction were used as antigens for detection of antibodies to $S$. enteritidis in serum and egg yolk of infected hens by agar gel preciptin test while SEF14 (a 14-KDa fimbrial protein) was not reactive (Holt et al. 2000). Immunization of chicks with $P$. aeruginosa whole cell proteins of strain $\mathrm{D}$ and E (20-205 KDa for each strain) and flagellin (53.277 $\mathrm{KDa}$ and $54.184 \mathrm{KDa}$, respectively) revealed high immunological responses and reduced infection in chicks but the whole cell oil adjuvant vaccine recorded best results than the flagellar oil adjuvant vaccine (Rabie and Zou El Fakar 2004).

\section{Fimbrial proteins}

Immunization of hens with Sef A and Fim A fimbrial proteins of $S$. enteritidis induced strong humoral immune response similar to that obtained with live bacteria. Sef A and Fim A can be considered as components of subunit vaccines (Kisiela et al. 2003)

\section{Pilus proteins}

Intranasal vaccination of broiler chickens with four avian pathogenic E. coli surface antigens, F pilus adhesin, $\mathrm{P}$ pilus adhesion, aerobactin receptor protein, and lipopolysaccharide (LPS) induced high immune response (high titer of $\operatorname{IgG}$, IgA, and $\operatorname{IgM}$ ) and did not induce the disease after challenge. They appear to be suitable candidates for a vaccine (Kariyawasam et al. 2002).

\section{Lipopolysaccharides}

Capsular polysaccharide subunit vaccines for E. coli can be prepared by extraction of capsular polysaccharide and soluble bacterial protein through water-bath inactivation and used for immunization of chickens and provided high protection (Shujian et al. 1996).

\section{Vaccines produced by recombinant DNA technology}

These vaccines depend upon identification or isolation of antigenic-coding gene. Then using recombinant technology transgenic implementation of the isolated gene in a bacterial vector like $E$. coli or yeast cells is performed. The expressed gene products of the grown culture is purified and used for immunization. Messenger RNA, which codes for the chosen proteins, is copied to produce a complementary DNA (cDNA) strand. This DNA strand can also be copied to produce a second strand. The double-stranded form of cDNA is then ligated to a cloning vector (plasmid) which is ready to be cloned using cloning host. The cloned recombinant DNA (rDNA) is then expressed by transformation into bacterial vector usually $E$. coli or yeast cells which act as production factories for the selected protein. The produced recombinant antigen is identified using selectable markers. These identified recombinant proteins could be injected into birds or animals as vaccine candidate (Babiuk et al. 2003). The immunization of chickens with a temperature-sensitive mutant $\mathrm{E} / 1 / 3$ of $S$. enteritidis induced strong protection against virulent $S$. entritidis strain after oral challenge and reduced the caecal and spleen colonization and the number of faecal shedding. (Cerquetti and Gheradi 2000). Salmonella DNA adenine methylase mutants prevent colonization of newly hatched chickens by homologous and heterologous serovars (Dueger et al. 2003). Gene E leads to emptying pasterulla cell envelops which are called bacterial ghosts. $P$. multocido and Pasteurella haemolytica (P. haemolytica) ghosts produced by expression of phage phi X174 lysis gene $\mathrm{E}$ are used as a vaccine for immunization of rabbits producing 100\% protection (Marchart et al. 2003). Three Campylobacter jejuni 72/D2/92 genes (CjaA (omph), cjac (hisj), and cjaD (omp18)) encoding immunodominant proteins are considered to be potential chicken vaccine candidates (Pawelec et al. 2000).

\section{DNA vaccines}

DNA encoding the gene of antigen protein is ligated to a plasmid. Direct inoculation of this plasmid DNA into the host tissues which is able to cause expression of the encoded antigen protein within the transfected cells. The expressed protein stimulates the host immune system to produce specific immune responses. DNA vaccine offers many advantages over the previously mentioned vaccines; there is no risk of infection, no purification costs, or antigen denaturation during preparation. Also, the endogenous synthesis of microbial antigen strongly enhances the cell mediated immunity; its strong stability reduces the costs of cold chains requirement by $80 \%$. DNA vaccines do not interfere with the maternal 
immunity and single dose can induce long term immunity (Oshop et al. 2002).

\section{Conclusion}

Protection studies against bacterial diseases were performed by using several trials: living vaccines (live attenuated vaccines; live, non-pathogenic microorganisms; live, low virulence microorganism)

Inactivated vaccines (heat-inactivated, chemical inactivates, radiation) are metabolic product vaccines (Toxoids), subunit vaccines (whole cell proteins, outer membrane proteins, purified flageller proteins (flagellin), fimbrial proteins, pilus proteins, lipopolysaccharides), vaccines produced by recombinant DNA technology, and DNA vaccines. The chicken farms must be care for using bacterial vaccines.

\section{Recommendations}

Bacterial vaccines need more investigations and researches because most farms depend on the use antibiotics for treatment when spread of bacterial diseases.

\begin{abstract}
Abbreviations
C. jejuni: Campylobacter jejuni; E. coli: Escherichia coli; $M$. gallisepticum: Mycoplasma gallisepticum; M. synoviae: Mycoplasma synoviae; NTG: Nitroguanidine; O. rhinotracheale: Ornithobacterium rhinotracheale; P. multocida: Pasteurella multocida; Ps. aeruginos: Pseudomonoas aeruginosa; S. enterica: Salmonella enterica; S. entertidis: Salmonella enteritidis; $S$. gallinarum: Salmonella gallinarium; S. gallolyticus: Streptococcus gallolyticus; S. typhimurium: Salmonella typhimurium
\end{abstract}

\section{Acknowledgements}

Not applicable

\section{Authors' contributions}

NSR and ZMSAG contributed to the data collection in addition to participating in writing the manuscript. Both authors read and approved the final manuscript.

\section{Funding}

Not applicable

\section{Availability of data and materials}

All data collected in this study are included in this published article.

\section{Ethics approval and consent to participate}

Yes (it is a review, not an experiment)

\section{Consent for publication}

Not applicable

\section{Competing interests}

The authors declare that they have no competing interests.

Received: 19 August 2019 Accepted: 18 December 2019

Published online: 29 January 2020

\section{References}

Abd-Aty EL, Rabie NS (2003) Immunogenic properties of outer memberane protein of C. jejuni in chicks. Vet Med J 51(1):95-104

Amoako KK, Prysliak T, Potter AA, Collinson SK, Kay WW, Allan BJ (2004) Attenuation of an avian pathogenic Escherichia coli strain due to a mutation in the rpsL gene. Avian Dis. 43:19-25

Babiuk LA, Gomis S, Hecker R (2003) Molecular approaches to disease control. Poult Sci 82(6):870-875
Babu U, Scott M, Myers MJ, Okamura M, Gaines D, Yancy HF, LillehoJ H, Heckert RA, Raybourne RB (2003) Effects of live attenuated and .killed Salmonella vaccine on T-lymphocyte mediated immunity in laying hens. Vet Immunol and Immunopathology 91(1):39-44

Bachtiar EW, Sheng K, Fifis T, Gamvrellis V, Plebanski M, Coloe PJ, Smooker PM (2003) Delivery of a heterologous antigen by a registered Salmonella vaccine (STM1). FEMS Microb Lett 277(2):211-217

Barbour EK, Hamadeh SK, Eidt A (2000) Infection and immunity in broiler chicken breeders vaccinated with a temperature-sensitive mutant of Mycoplasma gallisepticum and impact on performance of off spring. Poult Sci 79:17301735

Barman, T.K. . Sharma, VD and .Subodh, KU. (2000): Optimization of dose of Salmonella toxoid vaccine in poultry. Ind Vet J.79, (2)106-110

Barrow PA, Lovell MA, Stocker BAD (2000) Protection against experimental fowl typhoid by parenteral administration of live SL5828, an aro A-ser C (aromatic dependent) mutant of a wild-type S. Gallinarum Strain Made Lysogenic For p22 Sie Avian Path. 29(5):243-431

Berndt A, Methner U (2001) Gamma\ delta T cell response of chickens after oral administration of attenuated and non attenuated Salmonella typhimurium strains. Vet Immunol Immunopathol 78(2):143-161

Cambir S (1999) Avian colibacillosis, Salmonellosis and Pseudomonas prevention and control by Tribacto-pulvis inactivated vaccine. Revista Romana -deMedicina- veterinara 9(4):383-396

Cerquetti MC, Gheradi MM (2000) Orally administered attenuated salmonella enteritidis reduces chicken cecal carriage of virulent salmonella challenge organisms. Vet Microbiol 76(2):185-192

Chukiatsiri, K, Chotinun, S. and N. Chansiripornchai, 2010 An Outbreak of Avibacterium paragallinarum serovar B in a Thai Layer FarmThe Thai veterinary medicine 40(4):441-444 . December 2010.

Davies R, Breslin M (2004) Observations on Salmonella contamination of eggs from infected commercial laying flocks where vaccination for Salmonella enterica serovar Enteritidis has been used. Avian Pathol. 33:133-144

Dubreuil JD, Kostostrzynska M, Logan SM, Harris LA, Austin JW, Trust TJ (1990) Purification, characterization and localization of protein antigen shared by thermophilic Campylobacters. J Clin Microbiol June:1321-1328

Duchatel JP, Ree JM, Vindevogel H (1998) Evaluation of the optimal vaccine for vaccination trials of pigeons against paratyphoid by subcutaneous injection de. Medecine Veterinaire 142(1):35-38

Dueger EL, House JK, Heithoff DM, Mahan MJ (2003) Samonella DNA adenine methylase mutants prevent colcnization of newly hatched chickens by homologous and heterologous serovars. Int. J. of food Microb 80(2):153-159

Erganis O, Hadimli H, Solmaz H (2002) Vaccine development from serotypes O1, $\mathrm{O} 2$ and $\mathrm{O} 78$ of E.Coli against avian colibacillosis: layer chickens. Turk Ve Hayvancilik DEGISI 26(6):1213-1221

Faberwee A, Hartman EG, de Wit JJ, de Vries TS (2001) The spread of Salmonella gallinarum $9 R$ vaccine strain under field conditions. Avian Dis. 45(4):1024-1029

Fernchini A, Giacomini C, Manfreda G, Bertuzzi S (1997) Efficacy of inactivated vaccines against $S$. enteritidis experimental infection. ZOOTECNICA International 20(3):48-50

Frommer A, Freidlin PJ, Bock RR, Leitner G, Chaffer M, Heller ED (1994) Experimental vaccination of young chickens with a live-non pathogenic stran of E.coli. Avian Pathol. 23:425-433

Fukanoki S, Matsumoto K, Mori H et al (2000) Relation between antigen release and immune response of oil adjuvanted vaccines in chickens. J Vet Med Sci 62:571-574

Fukutome K, Watarai S, Mukamoto M, Kodama H (2001) Intestinal mucosal immune response in chickens following intraocular immunization with liposome-associated S. Enterica servor enteritidis antigen Developmental and comparative Immunology 25(5-6):475-484

Gong Y, Zhang P, Wang H et al (2014) Safety and efficacy studies on trivalent inactivated vaccines against infectious coryza. Vet Immunol Immunopathol 158:3-7

Hassan JO, Curtiss RI (1997) Efficacy of live aviruelnt S. typhimurium vaccine in preventing coionization and invasion of lyaing hens by $S$. typhimurium and $S$. enteritidis. Avian Dis 41(4):783-791

Hofacre CL, Glisson JR, Kleven SH (1987) Comparsion of vaccination protocols of broiler breeder hens for Pasteurella mutocida utilizing enzyme-linked immunosorbent assay and virulent challenge. Avian Dis. 31:260-263

Holt PS, Stone HD, Gast PK, Geen CR (2000) Application of the agar gel precipitin in test to detect antibodies to Salmonella enteric serovar enteritidis in serum and egg yolks from infected hens. Poult. Sci. 79(9):1246-1250 
Ito H, Nakatani H, Hayashi T (2000) Reaction of Japanese quail injected avian Samonella vaccine. Researsh Bulletin of the Aich-ken Agricultural Research Center 2000(32):247-250.

Jacobs, A.A.C., K.V. Berg and A.Malo, (2003) : Efficacy of a new tetravalent coryza vaccine against emerging variant type B strains. Avian path. 32 (3) $265-269$

Jang SI, Lillehoj HS, Lee S-H, Lee KW, Lillehoj EP, Hong YH, An D-J, Jeong W, Chun J-E, Bertrand F (2012) Vaccination with Clostridium perfringens recombinant proteins in combination with Montanide ${ }^{\mathrm{TM}}$ ISA 71 VG adjuvant increases protection against experimental necrotic enteritis in commercial broiler chickens. Vaccine. 30(36):5401-5406

Jiang Y, Mo H, Willingham C, Wang S, Park J-y, Kong W, Roland KL, Curtiss R III (2015) Protection against necrotic enteritis in broiler chickens by regulated delayed lysis Salmonella vaccines. Avian. Dis. 59(4):475-485

Kariyawasam S, Wilkie BN, Hunter DB, Gyles CL (2002) Systemic and mucosal antibody responses to selected cell surface antigens of avian pathogenic $E$ coli in experimentally infected chickens. Avian Dis. 46(3):668-678

Kaul ML, Tanwani SK, Sharda R (2001) Prleminaey studies on bactern against gangrenous dermatitis. Ind. Vet. J. 78(4):282-285.

Khafagy:A.A.R. A.M. Bayoumy and A.I.A.lbrahim (1999):Trial for enhancement of protection against snuffles in rabbits. Assiut VET.Med.j.42(83):371-378.

Khan MI, Fadal AA, Venkitanagrayanan KS (2003) Reducing colonization of Salmonella enteritidis in chicken by targeting outer membrane proteins of. Appl Microb 95(1):142-145

Kimpe A, Hermans K, de Herdt P, Haesebrouck F (2002) Failure of a low virulence Streptococcus gallolyticus serotype 1 strain to immunize pigeons against. Streptococcosis Avian Path 31(5):421-423

Kisiela D, Kuczkowski M, Wieliczko A, Sambor I, Mazurkiewicz M, Ugorski M (2003) Comparison of sefa,Film A. and Age fimbrial proteins of S.enteritidis in their abilities to elicit humoral immune response in hens. Bull Vet Inst In pulawy 47(1):95-105

Krüger A, Redmann T, Krajewski V (2008) Field investigations on the efficacy of a live vaccine of Salmonella enteritidis in meat turkeys. In: Hafez HM (ed) Proc of the $7^{\text {th }}$ International Symposium on Turkey Diseases. Verlag der DVG Service GmbH - ISBN 978-3-939902-96-6, Berlin, pp 300-311

Kulkarni R, Parreira V, Sharif S, Prescott J (2007) Immunization of broiler chickens against Clostridium perfringens-induced necrotic enteritis. Clin Vaccine Immunol. 14(9):1070-1077

Lam KM (1992) Use of a45 K Da protein in the detection of C.jejuni. Avian pathol 21:643-650

Ley DH, JM ML, Miles AM, Barnes HJ, Miller SH, Franz G (1997) Transmissibility of live Mycoplasma gallisepticum vaccine strain ts-11 and 6/85 from vaccinated layer pullets to sentinel poultry. Avian Dis 41(1):187-194

Lopes VC, Back A, Shin H, Halvorson DA, Nagaraja KV (2002) Development, characterization and preliminary evaluation of a temperature-sensitive mutant of Ornithobacterium rhinotracheale for potential use as a live vaccine in turkeys. Avian Dis 46(1):162-168

Marchart J, Dropmann G, Lechleitner S, Schlapp T, Wanner G, Szostak MP, Lubitz W (2003) Pasteurella mulltocida and Pasterulla haemolytica ghosts: new vaccine candidates. Vaccine 21:3988-3997

Markham JF, Morrow CJ, Whithear KG (1998) Efficacy of a temperature-sensitive M.synoviae live vaccine. Avian Dis 42:671-676

Mathner U, Keiling S, Kreutzer B, Schweinitz P (2002) Impact of maternal antipodies on the efficacy of immunisation of chicks with live Salmonella vaccine. Dtsch Tierarztl Wocchenschr 109(4):149-153

Mishra RS, Sharma VD (2001) Comparative efficacy of various toxoids against Salmonellosis in poultry. Vet Rss Comm 25(5):337-344

Mohamed M, El-Jakee J, Abo-Alyazeed H, Mossa I, Zahran AM (2002) R. efficacy of Ps. aeruginosa irradiated vaccine in chickens. Vet Med J Giza 50(2):709-719

Morrow CJ, Markham JE, Whithear KG (1998) production of temperature-sensitine clones of M.synoviae for evaluation as live vaccines. Avian Dis. 42:667-670

Nakae M, Sugahara Y, Yasui H, Imai C, Hasegwa Y, Osaka K, Shibasaki K (1997) Serotypes and drug susceptibility of Ps.aeruginosa isolated from clinical specimens. Japan. J Antibiot 50(2):187-197

Noor SM (1998) The mucosal and systemic immune responses in chickens orally immunized with C.jejuni antigen enterapped in polylactide-co-glycolide microparticles. J Immu-Ternak-den-Veteriner 3(4):264-269

Noor SM, Husband AJ, Widders RP (1995) An ova oral vaccination with C.jejuni established early development of intestnal immunity in chickens. Br Poultry Sci 36:563-573

Oshop GL, Elankumaran S, Heckert RA (2002) DNAvaccination in the avian. Vet Imm Immunopathol 89(1-2):1-12
Pawelec DP, Korasak D, Wyszynska AK, Rozynek E, Popowski J, Jagusztyn EK (2000) Genetic diversity of the Campylobacter genes coding immunodominant Proteins FEMS-Microbiol. Letters 185(1):43-49.

Peighambari, S.M, and C.L. Gyles (1998):Construction and characterization of avian E-coli cya crp mutants. Avian Dis.,42,4698-710.

Peighambari SM, Hunter DB, Shewen PE, Gyles CL (2002) Safety, immunogenicity, and efficacy of two E.coli cya crp mutants as vaccines for broilers. Avian Dis 46:287-297

Rabie NS, Kutkat MA (2002) Studies on the control of campylobacteriosis in chickens. 1-A trial of broiler immunization against C.jejuni INFECTION. J Egypt Vet Med Ass 62(6):167-177

Rabie Nagwa S, Sahar, El Fakar AZ (2004) Whole cell and flagellar proteins from Ps. aeruginosa: chicks protection studies. J Egypt Vet Med Ass Vol:64-62

Rappuoli R, Black S, Lambert PH (2011) Vaccine discovery and translation of new vaccine technology. The Lancet. 378(9788):360-368

Rashid M, Islam MA, Choudhury, Ahter M (2001) Immune responses of chickens against experimental developed inactivated E.coli vaccines. Bangladesh Veterinarian 18(2):105-113

Rock, TE; MD Samuel, PK. Swift and GS. Yarris(2000): Efficacy of a type c botulism vaccine in green -winged teal. J.OF WILDLIFE Dis., 36(3):489493.

Saif YM, Barnes HJ, Glisson JR, Fadly AM, McDougald LR, Swayne DE (2003) Diseases of poultry, 11th edn. lowa State University Press, Ames.

Scott, P. C., J. F. Markham and k. G. Whithear (1999): Safety and efficacy of two live Pasteurell multocida aro A mutant Vaccine. Avian Did. 43 (1):83-88.

Sharma JM (1999) Introduction to poultry vaccines and immunity. Adv Vet Med 41:481-494

Shujian H, Weiqing $L$, Jinhong $L$ (1996) Study on capsular polysaccharide subunit vaccines of E-coli pathogenic to chickens. Chinese J of Vet Med 22(6):50

Shuxia Z, Zengqi Y, Yufang Z, Yuemao Z, Dongyan F (1999) Diagnosis of ascites syndrome and its immunization with inactivated tissue vaccine. Chinese $J$ of Vet Med 25(6):13-14

Srivastava SK (1999) Immunogenicity of protein fractions of pasteurella multocida in animals. I nd J Anim Sci 69(9):653-656

Sunder JAl, Serivastava NC, Singh VP, Kumar M, Kumar A, Sunder J, Kumar M, Kumar A (2001) Humoral immune response in rabbits against Mycoplasma vaccine. I Nd J Anim Sci. 71(3):231-232

Turner AK, Barber LZ, Wigley P, Muhammed S, Jones MA, Lovell MA, Hume S, Barrow PA (2003) Contribution of Proton-translocating proteins to the virulence of Salmonella enterica serovars Typhimurium, Gallinarum, and Dublin in chickens and mice. Inf Imm. 71(6):3392-3401

Vereechen M, de Herdt P, Ducatelle R, Haesebrouck F (2000) The effect of vaccination on the course of an experimental Salmonella typhimurium infection in racing pigeons. Avian Path 29(5):465-471

Widders PR, Thomas LM, Long KA, Tokhi MA, Panaccio M, Apos E (1998) The specificity of antibody in chickens immunized to reduce intestinal colonization with C. jejuni. Vet Microbiol. 64:39-50

Wieliczko A, Stefaniak T, Spider A, Lugowski C, Mazurkiewicz M, Molenda J, Nikojczuk M (2000) Haemophilus sommus oral vaccine in the control of salmonella infections in poultry. Polish J Vet Sci. 3(2):87-92

Ziprin RL, Hume ME, Young CR, Harvey RB (2002) Inoculation of chicks with viable non - colonizing strains of $C$. jejuni: Evaluation of protection against colonizing strains. Curr Microbiol 44(3):221-223

\section{Publisher's Note}

Springer Nature remains neutral with regard to jurisdictional claims in published maps and institutional affiliations. 